\title{
Dimensi Brand Image Untuk Memprediksi Brand Love Dan Brand Loyaty
}

\author{
Wilson Frenredy dan Purnama Dharmawan \\ Program Studi Manajemen Fakultas Ekonomi \& Bisnis \\ Universitas Tarumanagara Jakarta \\ Email: Wilson.115150056@ stu.untar.ac.id
}

\begin{abstract}
The purpose of this research is to examine whether 1) mystery can predict brand love and brand loyalty Apple in Jakarta. 2) sensuality can predict brand love and brand loyalty Apple in Jakarta. 3) intimacy can predict brand love and brand loyalty Apple in Jakarta. 4) brand love can predict brand loyalty Apple in Jakarta. Sample was selected using convenience sampling method amounted to 198 respondents in Jakarta. The result of this study show that 1) mystery can positively predict the brand love Apple in Jakarta. While mystery cannot positively predict brand loyalty Apple in Jakarta. 2) sensuality cannot positively predict brand love Apple in Jakarta. While sensuality can positively predict brand loyalty Apple in Jakarta . 3) intimacy can positively predict brand love and brand loyalty Apple in Jakarta 4) Brand love can positively predict brand loyalty Apple in Jakarta.
\end{abstract}

Keywords: Brand Image Dimension (Mystery, Sensuality, Intimacy), Brand Love, Brand Loyalty

Abstrak: Tujuan dari penelitian ini adalah untuk menguji apakah 1) mystery dapat memprediksi brand love dan brand loyalty Apple di Jakarta 2) sensuality dapat memprediksi brand love dan brand loyalty Apple di Jakarta 3) intimacy dapat memprediksi brand love dan brand loyalty Apple di Jakarta 4) brand love dapat memprediksi brand loyalty Apple di Jakarta. Sampel dipilih menggunakan metode convenience sampling berjumlah 198 responden di Jakarta. Penelitian ini memperoleh hasil berupa 1) mystery dapat memprediksi secara positif terhadap brand love Apple di Jakarta. Sementara mystery tidak dapat memprediksi secara positif terhadap brand loyalty Apple di Jakarta. 2) sensuality tidak dapat memprediksi secara positif terhadap brand love Apple di Jakarta. Sementara sensuality dapat memprediksi secara positif brand loyalty Apple di Jakarta. 3) intimacy dapat memprediksi secara positif terhadap brand love dan brand loyalty Apple di Jakarta. 4) brand love dapat memprediksi secara positif brand loyalty Apple di Jakarta.

Kata Kunci: Dimensi Brand Image (Mystery, Sensuality, Intimacy), Brand Love, Brand Loyalty

\section{LATAR BELAKANG}

Di era globalisasi, dimana perkembangan teknologi yang semakin canggih, sangat berpengaruh terhadap persaingan dalam industri perdagangan. Setiap perusahaan berlombalomba menciptakan produk dengan inovasi-inovasi kreatif yang sama dan hampir serupa namun yang membedakan produk-produk tersebut salah satunya adalah brand.

Brand merupakan sebuah nama atau tanda pengenal yang digunakan oleh sebuah perusahaan dalam memproduksi barang yang dihasilkan yang digunakan agar konsumen mengenal atau mengingatnya. Definisi brand menurut AMA (American Marketing Association) "a name term, sign, symbol, or design, or a combination of them, intended to indentifity the goods and services of one seller or group of sellers and to differentiate the from those of competitors" (Kotler, 2009: 
258). Menurut Kotler (2009), unsur-unsur yang harus dimiliki oleh suatu brand, antara lain: nama brand, logo, tampilan visual seperti desain produk dan kemasan, tokoh perusahaan seperti maskot atau brand ambassador, suara seperti ikon bunyi atau nada, dan yang terakhir adalah slogan, tagline, atau jingle.

Hadirnya teknologi sangat berpengaruh dalam dunia pemasaran dan bisnis baik di dalam maupun di luar negeri. Di era globalisasi, hubungan teknologi dengan kegiatan bisnis sangat berdampak dalam dunia bisnis teknologi. Inovasi juga berpengaruh dalam bisnis, perkembangan teknologi dan juga kemajuan ekonomi. Menurut Zalrman dan Duncan (1997) inovasi adalah sebuah pengembangan dan implementasi gagasan ide dan praktek yang dianggap baru oleh seseorang suatu unit adopsi yang revelan dalam jangka waktu tertentu.

Tingginya persaingan dalam dunia pemasaran, menuntut setiap perusahaan agar memiliki keunggulan yang kompetitif dan mampu mempertahankan pelanggan dalam menghadapi persaingan bisnis dalam jangka panjang. Salah satunya adalah meningkatkan brand love pelanggan terhadap brand. Dengan meningkatnya kecintaan terhadap brand, maka diharapkan brand loyalty akan meningkat. Dengan demikian, penting bagi perusahan untuk meningkatkan brand love dan brand loyalty.

Salah satu faktor penting yang mampu mempengaruhi brand loyalty adalah brand image. Menurut Kotler dan Keller (2016) brand image merupakan persepsi pelanggan terhadap suatu brand sebagai refleksi dari asosiasi yang secara sederhana muncul dalam benak seorang pelanggan. Persepsi yang ada dalam pikiran seorang pelanggan terhadap suatu brand akan menimbulkan interaksi repurchase intention, ketika suatu brand mampu memberikan citra yang baik di mata seorang pelanggan akan membuat pelanggan memilih brand tersebut. Menurut Song, Bae, dan Han (2018) brand image memiliki tiga dimensi yang terdiri dari: mystery, sensuality, dan intimacy. Lebih lanjut, hasil penelitiannya menunjukkan brand image memiliki pengaruh positif terhadap brand loyalty.

Brand image disamping dapat menjelaskan brand loyalty, brand image juga dapat memengaruhi brand love. Menurut Carrol dan Ahuvia (2006) brand love merupakan tingkat ikatan emosional yang penuh gairah yang dimiliki pelanggan yang puas dengan brand tertentu. Menurut Low dan Lamb (2008) semakin baik brand image, maka akan semakin tinggi nilai brand dalam pandangan seorang konsumen sehingga membuat seorang pelanggan akan mencintai suatu brand. Hal tersebut sesuai dengan pernyataan Song, Bae, dan Han (2018) bahwa brand image terutama (mystery, sensuality, intimacy) memiliki pengaruh positif terhadap brand love.

Penelitian ini dilakukan dengan tujuan untuk melakukan pengujian secara empiris apakah dimensi brand image (mystery, sensuality,intimacy) dapat menjadi prediktor positif terhadap brand love dan brand loyalty. Diharapkan hasil dari penelitian ini dapat bermanfaat bagi perusahaan sebagai dasar dalam pengambilan keputusan dan perencanaan strategi pemasaran serta dapat memberikan informasi yang relevan terkait dengan variabel-variabel yang dapat memberikan pengaruh yang signifikan terhadap brand loyalty dan brand love.

\section{KAJIAN TEORI}

Pada penelitian ini, teori yang digunakan oleh peneliti adalah Theory of Planned Behavior (TPB). Theory of Planned Behavior (TPB) dikembangkan untuk mempelajari sikap dari perilaku tidak di bawah kendala individu.TRA (Theory of Reasoned Action) dikemukakan oleh Fishbien dalam Ajzen (1975). Brand image dapat dijelaskan melalui komponen behavioral belief adalah hal-hal yang diyakini oleh pelanggan dari sisi positif dan negatif. Sementara brand love dan brand loyalty dapat dijelaskan melalui komponen control belief. Control belief adalah pengalaman pribadi pelanggan dalam pengambilan keputusan. 
Brand image. Menurut Kotler dan Keller (2016:330) "brand image describes the extrinsic properties of the product or service, including the ways in which the brand attempts to meet customers' psychological or social needs". Brand image menjelaskan sifat ekstrinsik dari produk atau jasa termasuk cara dimana brand mencoba untuk memenuhi kebutuhan psikologi atau sosial pelanggan. Sementara menurut Keller (1993: 3) brand image adalah: "perceptions about a brand as reflected by the brand associations held in consumer memory". Persepsi yang ada dalam ingatan konsumen atau pelanggan terhadap suatu brand tertentu. Lebih lanjut menurut Arafat (2012: 41) brand image merupakan persepsi terhadap suatu brand yang dicerminkan oleh asosiasi suatu brand dalam ingatan seorang pelanggan yang mengandung makna bagi pelanggan yaitu kepercayaan pelanggan terhadap suatu brand tertentu. Berdasarkan definisi di atas maka dapat disimpulkan bahwa brand image adalah persepsi pelanggan terhadap suatu brand yang ada di dalam ingatan pelanggan. Menurut Robert (2005) terdapat tiga dimensi brand image, yaitu mystery, sensuality, dan intimacy.

Mystery. Menurut Cho dan Fiore (2015: 834) "mystery is conceptualized as a cognition-focused dimension of brand image, which reflects consumers "personal beliefs, thoughts and evaluations of a particular brand in relation to its products and service attributes, performance and brand meaning of a brand". Mystery adalah proses interaksi yang mencerminkan keyakinan dan pemikiran pelanggan dalam mengevaluasi suatu brand tertentu yang terbentuk oleh interaksi langsung maupun tidak langsung. Sementara menurut Robert (2005: 256) "Mystery draws together stories, metaphors, dreams and symbols. It is where past, present and future become one." Mystery menggabungkan cerita, metafora dan simbol dari masa lalu, sekarang dan masa depan menjadi satu. Lebih lanjut Cho dan Fiore (2015: 259) menjelaskan "four primary mystery themes emerged: 1) positive present experience; 2) positive memories from past experiences; 3) future aspirations 4) self-congruity. Berdasarkan ulasan di atas, maka dapat disimpulkan bahwa mystery adalah pengalaman pribadi seorang pelanggan yang terbentuk oleh interaksi masa lalu dan masa sekarang oleh brand tertentu yang mengungkapkan artibut yang tidak terkait dengan produk, misal harga dan citra pengguna.

Sensuality. Menurut Cho dan Fiore (2015: 835) "sensuality is conceptualized as a sensory focused dimension of brand image which is largely shaped by direct experiences with products and retail-environment-related attributes which lead to sensory gratification". Sensuality adalah proses yang terbentuk oleh pengalaman langsung seorang pelanggan terhadap sebuah produk ketika pelanggan menggunakan atau merasakan sendiri suatu produk tertentu.Sementara menurut Holbrook dan Hirschman (1982: 92) sensuality is "those facets of consumer behavior that relate to the multisensory, fantasy and emotive aspects of one experience with products". Aspek-aspek hubungan perilaku pelanggan terhadap suatu produk dari brand tertentu berdasarkan atas pengalaman pribadi seorang pelanggan. Lebih lanjut menurut Roberts (2005: 257) "Sensuality keeps the five senses on constant alert for new textures, intriguing scents and tastes, wonderful music. Sight, hearing, smell, touch, taste”. Sensuality lebih mengarahkan kepada panca indera pelanggan agar pelanggan berhati-hati dalam memilih produk terhadap suatu brand. Berdasarkan definisi di atas maka dapat disimpulkan bahwa sensuality merupakan pengalaman sensual pelanggan terhadap brand tertentu yang didasarkan oleh panca indera pelanggan seperti penciuman, pendengaran, sensasi sentuhan dan visual sehingga menimbulkan ikatan emosional.

Intimacy. Menurut Cho dan Fiore (2015: 836) "Intimacy is conceptualized as an emotional focused dimension of brand image and is largely shaped by subjective feelings such as 
excitement, happiness and joy". Intimacy adalah perasaan subjektif misal kegembiraan yang terbentuk ketika konsumen berinteraksi secara langsung dan tidak langsung dengan brand. Menurut Robert (2005: 257) "Intimacy means empathy, commitment and passion. The close connections that win intense loyalty as well as the small perfect gesture. These are often remembered long after functions and benefits have faded away." Intimacy dapat diartikan sebagai seberapa hubungan brand dengan pelanggan, tidak mungkin pelanggan bisa mencintai brand apabila brand yang bersangkutan tidak pernah melakukan interaksi dengan pelanggan. Tanpa intimacy, pelanggan tidak akan dapat merasakan bahwa telah berhasil memiliki brand tersebut. Lebih lanjut Cho dan Fiore (2015: 260) menjelaskan bahwa "three primary intimacy themes emerged: 1) the firm's empathy; 2) consumer commitment; 3) consumer enjoyment". Berdasarkan ulasan di atas maka dapat disimpulkan bahwa intimacy merupakan kedekatan hubungan pelanggan dengan brand tertentu yang terbentuk melalui suatu interaksi langsung maupun tidak langsung.

Brand Love. Menurut Carrol dan Ahuvia (2006: 81) brand love adalah "the level of emotional attachment that is full of satisfaction that satisfied consumers have over a particular brand". Tingkat keterikatan emosional yang penuh dengan kepuasan yang dimiliki konsumen atas merek tertentu. Menurut Fournier dan Mick (2009: 79) "brand love is conceptualized here as a mode satisfaction, i.e., a response experienced by some, but not all, satisfied consumers". Brand love dijelaskan sebagai mode kepuasan pelanggan yang membuat pelanggan mencintai suatu merek namun tidak semua pelanggan yang merasakan kepuasan mencintai suatu merek. Lebih lanjut Ranjbarian et al. (2013:181) "brand Love can occur when a customer can see a brand as a brand individuals they can love like loving someone". Brand love akan terjadi pada saat pelanggan menganggap bahwa suatu brand sebagai individu yang pelanggan cintai. Berdasarkan definisi di atas maka dapat disimpulkan bahwa brand love merupakan kecintaan dan kasih sayang pelanggan atas suatu brand yang memberikan kepuasan dan kebanggaan tersendiri bagi pelanggan dalam menggunakan suatu brand.

Brand Loyalty. Menurut Kotler dan Keller (2016: 176) "loyalty is a deeply held commitment to re-buy or re-patronize a prefered product or service in the future despite situational influences and marketing efforts having the potential to cause switching behaviour". Kesetiaan merupakan komitmen yang dipegang secara mendalam dalam membeli atau mendukung kembali produk atau jasa yang disukai di masa depan meski pengaruh situasi dan usaha pemasaran berpotensi menyebabkan pelanggan beralih. Menurut Olivier (2009:34) "brand loyalty associated with a commitment to repurchase or use products and services, which are very consistent in the future, and thus make repeated purchases from the same brand or company, handle the situation and improve marketing that encourages policy changes". Keberadaan komitmen mendalam untuk membeli kembali atau menggunakan produk dan layanan, yang sangat konsisten di masa depan. Lebih lanjut menurut Aaker (2009:36) "brand loyalty is a measure of customer relationship to a brand". Brand loyalty menunjukkan adanya suatu ikatan antara pelanggan dengan suatu brand tertentu dan hal ini ditandai dengan adanya niat utuk membeli kembali. Berdasarkan definisi di atas maka dapat disimpulkan bahwa, brand loyalty merupakan kesetiaan konsumen atas suatu brand dimana konsumen memiliki hubungan jangka panjang dengan brand dan tidak akan beralih ke brand lain.

Kaitan antara mystery dan brand love. Song, Bae, dan Han (2018) menjelaskan bahwa mystery memiliki keterkaitan secara positif terhadap brand love. Mystery dalam hal ini mengacu pada pengalaman kognitif pelanggan yang terbentuk melalui aspek-aspek mitos dari budaya tertentu, mendapatkan inspirasi dan menggabungkan masa lalu, sekarang, dan masa depan dengan suatu 
brand tertentu. Pendapat dan preferensi konsumen, komitmen jangka panjang mereka terhadap suatu merek dan interaksi merek-konsumen berkontribusi untuk membangkitkan emosi positif terhadap suatu merek. Oleh karena itu dapat diasumsikan bahwa mystery dapat membuat pelanggan memiliki brand love yang kuat terhadap suatu brand. Rodrigues dan Rodrigues (2019) menyatakan bahwa evaluasi positif dari suatu brand dapat berkontribusi untuk mencintai brand. Berdasarkan uraian di atas, hipotesis pertama adalah: H1: mystery dapat memprediksi secara positif terhadap brand love.

Kaitan antara sensuality dan brand love. Song, Bae, dan Han (2018) menjelaskan bahwa sensuality memiliki keterkaitan secara positif terhadap brand love. Dalam hal ini sensuality mengacu pada pengalaman nyata yang dibangun melalui suatu brand dengan menggunakan panca indera pelanggan. Brand love akan timbul saat seorang konsumen merasakan sensualitas. Rodriguez dan Rodriguez (2019) menyatakan bahwa pengalaman merek sensual konsumen memiliki pengaruh yang signifikan terhadap pengembangan sikap positif mereka terhadap brand secara langsung dan tidak langsung. Berdasarkan uraian di atas, hipotesis kedua adalah: $\mathrm{H} 2$ : sensuality dapat memprediksi secara positif terhadap brand love.

Kaitan antara intimacy dan brand love. Song, Bae, dan Han (2018) menjelaskan bahwa intimacy memiliki keterkaitan secara positif terhadap brand love. Intimacy dalam hal ini mengacu pada tingkatan pelanggan dan suatu brand secara emosional. Menurut Cho dan Fiore (2015) kesenangan dan komitmen jangka panjang pelanggan dilabuhkan pada saat konsumen berinteraksi dengan brand. Rodriguez dan Rodriguez (2019) menyatakan brand love mengacu pada tingkat dimana pelanggan memiliki kasih sayang yang kuat dan ikatan emosional tertentu dengan suatu brand. Berdasarkan uraian di atas, maka hipotesis ketiga adalah: H3: Brand experience dapat memprediksi secara positif terhadap brand trust.

Kaitan antara mystery dan brand loyalty. Song, Bae, dan Han (2018) menjelaskan bahwa mystery memiliki keterkaitan secara positif dengan brand loyalty. Menurut Cho, Fiore dan $\mathrm{Yu}$ (2017) seorang pelanggan akan memberikan rasa loyaltitas yang tinggi terhadap suatu brand ketika pelanggan jatuh cinta dengan suatu brand dan percaya bahwa brand mampu mempertahankan dan meningkatkan kinerja yang baik. Kinerja yang baik mencerminkan asosiasi kognitif termasuk kualitas fisik, daya tahan, layanan, efektivitas dan efisiensi brand. Berdasarkan uraian di atas, hipotesis keempat adalah: H4: mystery dapat memprediksi secara positif terhadap brand loyalty

Kaitan antara sensuality dan brand loyalty. Song, Bae, dan Han (2018) menjelaskan bahwa sensuality memiliki keterkaitan secara positif dengan brand loyalty. Elemen sensorik dari suatu brand dapat memengaruhi perasaan senang dan gairah seorang pelanggan. Menurut Cho, Fiore, dan $\mathrm{Yu}$ (2017) elemen sensorik, seperti bahan yang digunakan brand terhadap suatu produk dapat membuat pelanggan mencintai suatu brand sehingga mampu menciptakan hubungan jangka panjang antara brand dengan pelanggan. Berdasarkan uraian di atas, hipotesis kelima adalah: H5: sensualtiy dapat memprediksi secara positif terhadap brand loyalty.

Kaitan antara intimacy dan brand loyalty. Song, Bae, dan Han (2018) menjelaskan bahwa intimacy memiliki keterkaitan secara positif terhadap brand loyalty. Pentingnya ikatan antara pelanggan dengan brand akan membangkitkan perasaan cinta terhadap sebuah brand. Cho, Fiore dan Yu (2017) menjelaskan apabila seorang pelanggan telah memiliki perasaan positif terhadap suatu brand maka akan semakin meningkatkan rasa loyaltitas yang tinggi. Berdasarkan uraian di 
atas, hipotesis keenam adalah: H6: intimacy dapat memprediksi secara positif terhadap brand loyalty.

Kaitan antara brand love dengan brand loyalty. Song, Bae, dan Han (2018) menjelaskan bahwa brand love memiliki keterkaitan secara positif terhadap brand loyalty. Cho dan Fiore (2015) menegaskan bahwa brand love telah dianggap sebagai elemen emosional yang signifikan faktor dengan konsumen, karena hal itu menyebabkan hubungan positif jangka panjang (peningkatan brand loyalty) termasuk hubungan jangka pendek (peningkatan konsumsi sementara). Berdasarkan uraian di atas, hipotesis ketujuh adalah H7: brand love dapat memprediksi secara positif terhadap brand loyalty

Berdasarkan kaitan-kaitan antar variabel di atas, maka model penelitian yang dirumuskan adalah sebagai berikut:

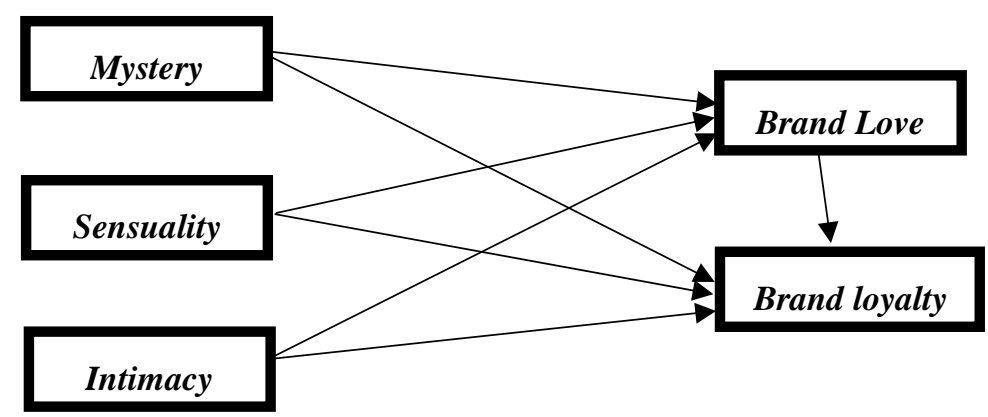

Gambar 1. Model Penelitian

\section{METODOLOGI}

Desain penelitian deskriptif mendeskripsikan karakteristik suatu variabel penelitian. Pendekatan desain penelitian deskriptif dalam penelitian ini menggunakan single cross-sectional design, dikarenakan hanya dilakukan sekali dan beberapa sampel yang diambil berasal dari elemen populasi.

Penelitian ini melibatkan 198 responden. Sampel yang digunakan dalam penelitian ini adalah pelanggan brand Apple di Jakarta yang berusia 16-50 tahun. Peneliti menggunakan nonprobability sampling dalam melakukan pengambilan sampel dengan teknik pemilihan sampel adalah convenience sampling.

Tabel 1. Variabel Data Pengukuran

\begin{tabular}{|c|c|c|}
\hline Variabel & Item & Sumber \\
\hline Mystery & 6 item & Song, Bae dan Han (2019); Rodrigues dan Rodrigue (2019) \\
\hline sensuality & 6 item & Song, Bae dan Han (2019); Rodrigues dan Rodrigue (2019) \\
\hline Intimacy & 7 item & Song, Bae dan Han (2019); Rodrigues dan Rodrigue (2019) \\
\hline Brand Love & 5 item & Song, Bae dan Han (2019); Rodrigues dan Rodrigue (2019) \\
\hline Brand Loyalty & 6 item & Song, Bae dan Han (2019) \\
\hline
\end{tabular}


Penelitian ini menggunakan kuisioner sebagai instrumen pengumpulan data yang didistribusikan secara online dengan menggunakan google form. Penelitian ini menggunakan skala Likert 5 poin dengan 1 menunjukan "sangat tidak setuju" dan 5 menunjukan "sangat setuju". Setelah dilakukan analisis validitas dan reliabilitas, 30 item pengukuran di atas memiliki nilai AVE di atas 0,5 nilai loading factor di atas 0,7 dimana hal tersebut telah memenuhi kriteria validitas konvergen, serta telah memenuhi kriteria validitas diskriminan fornell-larcker dan cross-loadings. Lebih lanjut, hasil analisis reliabilitas menunjukan bahwa semua variabel memiliki nilai Cronbach's Alpha dan Composite Reliability di atas 0,7 yang mengindikasi variabel dalam penelitian tersebut reliabel (Larcker, 2009).

\section{Hasil Uji Statistik}

Berikut hasil pengujian bootstraping secara singkat tertera pada tabel 2

Tabel 2. Hasil Pengujian Hipotesis

\begin{tabular}{|l|c|c|c|}
\hline \multicolumn{1}{|c|}{ Variabel } & $\begin{array}{c}\text { Path } \\
\text { Coefficient }\end{array}$ & t-statistics & p-value \\
\hline Mystery $\rightarrow$ Brand Love & 0,237 & 3,971 & 0,000 \\
\hline Sensuality $\rightarrow$ Brand Love & 0,093 & 1,599 & 0,111 \\
\hline Intimacy $\rightarrow$ Brand Love & 0,620 & 9,349 & 0,000 \\
\hline Mystery $\rightarrow$ Brand Loyalty & $-0,023$ & 0,384 & 0,701 \\
\hline Sensuality $\rightarrow$ Brand Loyalty & 0,152 & 2,244 & 0,025 \\
\hline Intimacy $\rightarrow$ Brand Loyalty & 0,319 & 4,254 & 0,000 \\
\hline Brand Love $\rightarrow$ Brand Loyalty & 0,489 & 6,637 & 0,000 \\
\hline
\end{tabular}

\section{DISKUSI}

Berdasarkan hasil pengujian hipotesis pertama bagian (H1) menunjukan mystery terbukti dapat memprediksi secara positif brand love, sehingga dapat disimpulkan bahwa H1 tidak ditolak. Hasil pengujian hipotesis tersebut tidak sesuai dengan penelitian terdahulu yang dilakukan oleh Song, Bae, dan Han (2018) yang menyatakan mystery memiliki pengaruh positif terhadap brand love. Rodrigues dan Rodrigues (2019) menyatakan bahwa evaluasi positif dari suatu brand dapat berkontribusi untuk mencintai brand. Ketika seorang pelanggan memiliki pengalaman yang baik, mengesankan dan mampu membangun pengalaman yang menyenangkan ketika menggunakan produk dari brand, maka dapat dikatakan brand telah memenuhi kebutuhan pelanggan dengan baik, hal ini mampu menciptakan kecintaan dari pelanggan terhadap brand.

Berikutnya, berdasarkan hasil pengujian hipotesis kedua bagian $(\mathrm{H} 2)$ menunjukan sensuality terbukti tidak dapat memprediksi secara positif brand love, sehingga dapat disimpulkan bahwa $\mathrm{H} 2$ ditolak. Hasil pengujian hipotesis tersebut tidak sesuai dengan penelitian terdahulu yang dilakukan oleh oleh Song, Bae, dan Han (2018) yang menyatakan sensuality memiliki pengaruh positif terhadap brand love.

Berdasarkan hasil pengujian hipotesis ketiga bagian (H3) menunjukan intimacy terbukti dapat memprediksi secara positif brand love, sehingga dapat disimpulkan bahwa $\mathrm{H} 3$ tidak ditolak. Hasil penelitian ini sesuai dengan penelitian terdahulu yang dilakukan oleh Song, Bae, dan Han (2018) yang menyatakan bahwa intimacy merupakan prediktor positif terhadap brand 
love. Menurut Cho dan Fiore (2015) kesenangan dan komitmen jangka panjang pelanggan dilabuhkan pada saat konsumen berinteraksi dengan brand.

Selanjutnya hasil pengujian hipotesis keempat bagian (H4) menunjukan intimacy terbukti tidak dapat memprediksi secara positif brand loyalty, sehingga dapat disimpulkan bahwa H4 ditolak. Hasil pengujian hipotesis tersebut tidak sesuai dengan penelitian terdahulu yang dilakukan oleh oleh Song, Bae, dan Han (2018) yang menyatakan mystery memiliki pengaruh positif terhadap brand loyalty.

Berdasarkan hasil pengujian hipotesis kelima (H5) menunjukan bahwa sensualtiy terbukti dapat memprediksi secara positif brand loyalty, sehingga dapat disimpulkan bahwa H5 tidak ditolak. Hasil penelitian ini sesuai dengan penelitian terdahulu yang dilakukan oleh Song, Bae, dan Han (2018) yang menyatakan sensuality memiliki pengaruh positif yang signifikan terhadap brand loyalty. Menurut Cho, Fiore dan Yu (2017) elemen sensorik, seperti bahan yang digunakan brand terhadap suatu produk dapat membuat pelanggan mencintai suatu brand sehingga mampu menciptakan hubungan jangka panjang antara brand dengan pelanggan.

Berdasarkan hasil pengujian hipotesis keenam (H6) menunjukan bahwa intimacy terbukti dapat memprediksi secara positif brand loyalty, sehingga dapat disimpulkan bahwa H6 tidak ditolak. Hasil pengujian hipotesis ini sesuai dengan penelitian yang dilakukan oleh Song, Bae, dan Han (2018) yang menyatakan intimacy memiliki pengaruh positif yang signifikan terhadap brand loyalty. Cho, Fiore dan Yu (2017) menjelaskan apabila seorang pelanggan telah memiliki perasaan positif terhadap suatu brand maka akan semakin meningkatkan rasa loyaltitas yang tinggi.

Selanjutnya, hasil pengujian hipotesis terakhir yaitu hipotesis ketujuh (H7) menunjukan bahwa brand love terbukti dapat memprediksi secara positif brand loyalty, sehingga dapat disimpulkan bahwa $\mathrm{H} 7$ tidak ditolak. Hasil pengujian hipotesis ini sesuai dengan penelitian yang dilakukan oleh Song, Bae, dan Han (2018) yang menyatakan brand love memiliki pengaruh positif yang signifikan terhadap brand loyalty. Cho dan Fiore (2015) menegaskan bahwa brand love telah dianggap sebagai elemen emosional yang signifikan faktor dengan konsumen, karena hal itu menyebabkan hubungan positif jangka panjang (peningkatan brand loyalty) termasuk hubungan jangka pendek (peningkatan konsumsi sementara).

\section{KESIMPULAN DAN SARAN}

Kesimpulan yang dapat diambil berdasarkan hasil penelitian ini adalah mystery merupakan prediktor yang signifikan dan positif terhadap brand love, namun mystery tidak dapat menjadi prediktor yang signifikan dan positif terhadap brand loyalty. Selain itu, hasil penelitian ini juga menemukan bahwa sensuality dapat menjadi prediktor yang signifikan dan positif terhadap brand love, namun sensuality tidak dapat menjadi prediktor yang signifikan dan positif terhadap brand love. Intimacy merupakan prediktor yang signifikan dan positif terhadap brand love dan brand loyalty. Hasil penelitian ini menemukan bahwa brand love merupakan prediktor yang signifikan terhadap brand loyalty.

Peneliti menyarankan agar suatu brand terus memberikan pengalaman yang baik dan tak terlupakan bagi pelanggan. Berdasarkan hasil penelitian ini, alasan pelanggan lebih memilih suatu brand daripada brand lain dikarenakan inovasi dari produk suatu brand yang selalu membuat inovasi-inovasi baru mengikuti perkembangan teknologi dan memberikan sesuatu yang baru terhadap produknya sehingga hal tersebut menjadi kejutan bagi pelanggan. Selain itu, pelanggan lebih memilih suatu brand daripada brand lain karena kualitas produk suatu brand yang tinggi dan eksklusif dibandingkan dengan brand lain. 
Untuk penelitian selanjutnya, disarankan untuk menambah jumlah sampel yang diteliti serta memperluas jangkauan wilayah yang diteliti, sehingga penelitian selanjutnya akan lebih akurat dan memperkuat penelitian sebelumnya yang memiliki karaktersitik responden yang berbeda.

\section{DAFTAR PUSTAKA}

Aaker, D. A. (1991). Managing Brand Equity: Capitalizing on the Value of a Brand Name. New York: The Free Press.

Albert, N., Merunka, D. and Valette-Florence, P. (2008), “When consumers love their brands: exploring the concept and its dimensions", Journal of Business Research, Vol. 61 No. 10, pp. 1062-1075.

Chaudhuri, A. and Holbrook, M.B. (2001). The chain of effects from brand trust and brand affect to brand performance: the role of brand loyalty. Journal of Marketing, 65(2), pp. 81-93.

Chao-Chin Huang. (2017). " The impacts of brand experiences of brand loyalty mediators of brand love and trust" Management Decision Vol. 55 no. 5, pp. 915- 934.

Cho, E. and Fiore, A.M. (2015), "Conceptualization of a holistic brand image measure for fashion-related brands", Journal of Consumer Marketing, Vol. 32 No. 4, pp. 255-265.

Cho, E., Fiore, A.M. and Russell, D.W. (2015), "Validation of a fashion brand image scale capturing cognitive, sensory, and affective associations: testing its role in an extended Brand equity model", Psychology \& Marketing, Vol. 32 No. 1, pp. 28-48.

Cho, E. (2018), "Impact of fashion innovativeness on consumer-based brand equity", Journal of Consumer Marketing, Vol. 35 No. 3, pp. 340-350.

Carroll, B.A. and Ahuvia, A.C. (2006), "Some antecedents and outcomes of brand love", Marketing Letters, Vol. 17 No. 2, pp. 79-89.

Eunjoo Cho. "Development of a brand image scale and the impact of the lovemarks on brand equity" Love/Respect Axis Separating Lovemarks from Brands, Fads, and Products (Roberts, 2006, pp. 18)

Eunjoo Cho, Ann Marie Fiore. (2015), "Conceptualization of a holistic brand image measure for fashion- related brands " Journal of Consumer Marketing 42/4, pp. 255-265

Fornell, C., \& Larcker, D. F. (1981). Evaluating Structural Equation Model with Unobservable Variables and Measurement Error. Journal of Marketiong Research, pp.39-50

Fournier, Mick. (2009), "Consumers and their brands: developing relationship theory in consumer research", Journal of Consumer Research, Vol. 24 No. 4, pp. 343-379.

Garson, G. D. (2016), Partial Least Squares: Regression \& Structural Equation Models. Statistical Associates Publishing.

Ghozali, Imam. (2014). Structural Equation Modeling, Metode Alternatif dengan Partial Least Square (PLS). Edisi 4. Semarang : Badan Penerbit Universitas Diponegoro.

Hair, J. F., Ringle, C. M., \& Sarstedt, M. (2011). PLS-SEM: Indeed a silver bullet. Journal of Marketing theory and Practice, 19 (2), pp. 139-152.

Hair, J.F., Black, W.C., Babin, B.J., Anderson, R.E. and Tatham, R.L., (2014). Multivariate data analysis (Vol. 7).

Hak Jun Song, So Young Bae, Heesup Han, (2019) "Emotional comprehension of name- brand coffe shop: focus on lovemarks theory". International Journal of Contemporary Hospitality Management Vol. 31 No 3.

Hogan, R.M. and Hunt, S.D. (1994), "The commitment-trust theory of relationship marketing", Journal of Marketing, Vol. 58 No. 3, pp. 20-38. 
Holbrook, M.B. and Hirschman, E.C. (1982), "The experiential aspects of consumption: consumer fantasies, feelings, and fun”, Journal of Consumer Research,Vol. 9 No. 2 , pp. 132-140.

Keller, K. L. (1993). Conceptualizing, Measuring, and Managing Consumer-Based Brand Equity. Journal of Marketing, 57, pp. 1-22

Keller, K.L. (2013). Strategic Brand Management: Building, Measuring, and Managing Brand Equity. Unites States : Pearson Education, Essex.

Kotler, P. and Keller, K.L. (2009), Marketing Management, $13^{\text {th }}$ ed., Prentice-Hall, Upper SaddleRiver, NJ.

Kotler, Philip and Kevin Lane Keller, (2016). Marketing Management, $15^{\text {th }}$ Edition, Pearson Education,Inc.

Low, G.S. and Lamb, C.W. (2000), "The measurement and dimensionality of brand associations", Journal of Product and Brand Management, Vol. 9 No. 6, pp. 350-368.

Lee, Y.K., Back, K.J. and Kim, J.Y. (2009), "Family restaurant brand personality and its impact on customer's emotion, satisfaction, and brand loyalty", Journal of Hospitality and Tourism Research, Vol. 33 No. 3, pp. 305-328.

Oliver, R.L. (1999). Whence consumer loyalty?. The Journal of Marketing, 63, pp. 33-44.

Roberts, K. (2005), Lovemarks: The Future Beyond Brands, $2^{\text {nd }}$ ed., Powerhouse Books, New York, NY.

Roberts, K. (2006), The Lovemarks Effect, British Brands Group.

Rodrigues, Clarinda., Rodrigues, Paula. (2019). "Brand love matters to Millennials: the relevance of mystery, sensuality, and intimacy to neo-luxury brands" Journal of Product \& Brand Management 28/7, pp. 830-848

Roscoe, J. T. (1975). Fundamental research statistics for the behavioral sciences [by] John T. Roscoe.

Sholihin, M. \& Ratmono, D. (2013). Analisis SEM-PLS dengan WarpPLS 3.0 untuk Hubungan Nonlinier dalam Penelitian Sosial dan Bisnis. Yogyakarta: C.V ANDI OFFSET

Tenenhaus, M., Vinzi, V. E., Chatelin, Y. M., \& Lauro, C. (2005). PLS path modeling. computational statistics \& data analysis, 48(1), pp. 159-205. 